\title{
How much will the data allow us to know?
}

\author{
Karl F. Welke, MD, MS \\ From the Division of Congenital Cardiothoracic Surgery, Department of Surgery, University of Illinois College of \\ Medicine and the Children's Hospital of Illinois, Peoria, Ill. \\ Disclosures: Author has nothing to disclose with regard to commercial support. \\ Received for publication Sept 28, 2015; accepted for publication Sept 29, 2015; available ahead of print Oct 29, \\ 2015. \\ Address for reprints: Karl F. Welke, MD, MS, Division of Congenital Cardiothoracic Surgery, University of Illi- \\ nois College of Medicine and the Children's Hospital of Illinois, 420 NE Glen Oak Ave, Suite 301, Peoria, IL \\ 61603 (E-mail: karl.f.welke@osfhealthcare.org). \\ J Thorac Cardiovasc Surg 2016;151:466-7 \\ $0022-5223 / \$ 36.00$ \\ Copyright (c) 2016 by The American Association for Thoracic Surgery \\ http://dx.doi.org/10.1016/j.jtcvs.2015.09.123
}

In their article in this issue of the Journal, Lewis and colleagues ${ }^{1}$ present a single-institution, retrospective cohort study of patients with moderate or greater tricuspid regurgitation who underwent cardiac surgery for nontricuspid regurgitation related indications. The median age of the 107 patients was 41 years. The patients were followed up for as long as 3 years after surgery. Lewis and colleagues ${ }^{1}$ report a positive association between moderate or greater tricuspid regurgitation remaining after surgery and the composite primary outcome of death, heart transplant, or reoperation on the tricuspid valve. Although lack of tricuspid valve repair or replacement was positively associated with a greater risk of persistent moderate or greater tricuspid regurgitation, intervention on the tricuspid valve was neither positively nor negatively associated with the composite primary outcome.

Lewis and colleagues ${ }^{1}$ have addressed an important and unsettled question. Many physicians have treated tricuspid regurgitation as a relatively benign lesion; however, the presence of tricuspid regurgitation with time is associated with both reduced functional capacity and reduced longterm survival. ${ }^{2,3}$ In the congenital cardiac population, tricuspid regurgitation has a variety of etiologies, and the potential for benefit of intervention on the tricuspid valve may depend on the etiology. Valve repair or replacement may be more likely to result in improved outcomes when an abnormality of the valve is the primary problem. Such strategies may be less effective when valve dysfunction is related to a nonvalvular condition, such as pulmonary hypertension or right ventricular dilation. In these cases, the patient's course may be more influenced by the primary problem than by the tricuspid valve function. Although Lewis and colleagues ${ }^{1}$ did not find an association between any single diagnosis and the composite primary outcome, 13 of 17 patients $(76 \%)$ who reached the primary outcome had tetralogy of Fallot or pulmonary stenosis, compared with 36 of $90(40 \%)$ of those who did not. This may represent a group of patients with annular dilation related to right ventricular dilation and dysfunction rather

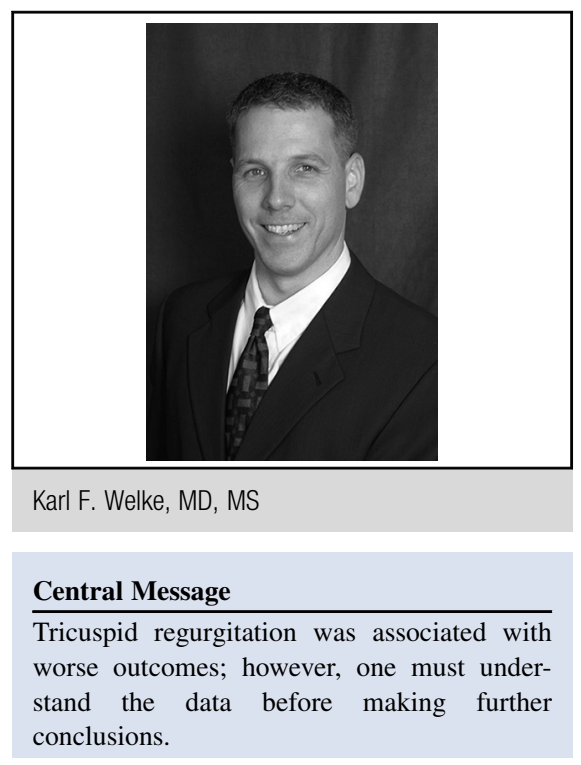

See Article page 460 .

than structural tricuspid valve abnormalities. More detail as to the cause of the tricuspid regurgitation would help one to understand which patients could benefit from intervention. In addition, the inclusion of functional status, including patient-reported health status, as a dependent variable might further inform decision making by providing a patient-centered outcome.

The biases inherent in a single-center, retrospective study of a limited number of operations occurring through an extended period (21 years) complicate the interpretation of the results. The finding that only 5 patients per year met inclusion criteria in a busy center illustrates one challenge in conducting research in adult congenital heart surgery. Because of the low incidence of any single outcome measure, Lewis and colleagues ${ }^{1}$ chose to use a composite measure, consisting of 3 outcomes that represented cardiac dysfunction or failure, as the primary dependent variable. Still, the numbers of patients who reached the primary and secondary end points were small, limiting the reliability of the multivariable models. At ratios of less than 10 events per independent variable, regression coefficients may be biased, confidence limits surrounding estimates may not have proper coverage, Wald estimates may be conservative under the null hypothesis, and paradoxic associations may increase. ${ }^{4}$ Although there may be circumstances in which this rule may be relaxed, ratios of 4 or fewer events per independent variable are problematic, especially when the number of events is 30 or less. ${ }^{5}$ In the study of Lewis and colleagues, ${ }^{1}$ the numbers of events were 
17 and 31 , and the events per independent variable were 2.8 and 5.2, respectively, in the models for the primary and secondary outcomes. This does not negate the results, but is important for the readers to know when considering how to modify their practice.

Although the findings of this study may support one's belief that the tricuspid valve should be repaired or replaced when moderate or greater regurgitation is present, one must be conscious of the limitations of the data and the methodology. The results should be considered in the context of the broader literature on the topic, which is not definitive. The surgeon is left to use his or her judgment regarding when to intervene, knowing that repair of a tricuspid valve without Epstein morphology in an adult is an intervention that can usually be performed without significant added morbidity and, depending on the etiology, may improve outcomes, including functional status and longevity. More often than not, this is the most guidance that our literature can provide.

\section{References}

1. Lewis MJ, Ginns JN, Ye S, Chai P, Quaegebeur JM, Bacha E, et al. Postoperative tricuspid regurgitation following adult congenital heart surgery is associated with adverse clinical outcomes. J Thorac Cardiovasc Surg. 2016;151:460-5.

2. Koelling TM, Aaronson KD, Cody RJ, Bach DS, Armstrong WF. Prognostic significance of mitral regurgitation and tricuspid regurgitation in patients with left ventricular systolic dysfunction. Am Heart J. 2002;144:524-9.

3. Kim YJ, Kwon DA, Kim HK, Park JS, Hahn S, Kim KH, et al. Determinants of surgical outcome in patients with isolated tricuspid regurgitation. Circulation. 2009;120:1672-8.

4. Peduzzi P, Concato J, Kemper E, Hord TR, Feinstein AR. A simulation study of the number of events per variable in logistic regression analysis. J Clin Epidemiol. 1996;49:1373-9.

5. Vittinghoff E, McColloch CE. Relaxing the rule of ten events per variable in logistic and Cox regression. Am J Epidemiol. 2007;165:710-8. 